LICENÇA CC BY:

Artigo distribuído sob os termos

Creative Commons, permite uso e distribuição irrestrita em qualquer meio desde que o autor credite a fonte original.

\section{CINEMA E DIREITOS HUMANOS NA ESCOLA: ESTRATÉGIAS PARA A SUPERAÇÃO DA VIOLÊNCIA}

CINEMA AND HUMAN RIGHTS IN SCHOOLS: STRATEGIES FOR

OVERCOMING VIOLENCE

CINE Y DERECHOS HUMANOS EN LA ESCUELA: ESTRATEGIAS PARA SUPERAR LA VIOLENCIA

Alexandre Silva Guerreiro'

'Secretraria de Estado de Educação, Rio de Janeiro, RJ, Brasil.

Aprovado em: 02/11/2020

Resumo: Cinema, educação e direitos humanos formam uma importante tríade a partir da qual devemos repensar nossas práticas docentes. O cinema está presente na escola de diversas formas, mas o campo formado a partir da junção do cinema com a educação originou pesquisas que refletem sobre o cinema na escola como alteridade, questionando seu uso como mero apoio pedagógico. Os direitos humanos têm uma contribuição fundamental a dar nesse processo na medida em que trazem para essa reflexão uma dimensão ética e estética da Audiovisão (CHION, 2011). Por outro lado, podemos considerar que um cenário de violência escolar só pode existir na ausência dos direitos humanos. Esse trabalho propõe uma reflexão sobre o cinema na escola, observando o conceito de Curadoria Educativa (VERGARA, 1996) como peça chave no combate à violência e como garantidor de uma Educação em direitos humanos.

Palavras-chave: Cinema; Educação; Direitos Humanos.

Abstract: Cinema, education and human rights form an important triad on which we should rethink our teaching practices. The cinema is present in the school in several ways, but the field that is formed when cinema is used for educational purposes has led to research on cinema in school as alterity, investigating its use as a mere pedagogical support. Human rights make a fundamental contribution to this process, as they bring to this issue an ethical and aesthetic dimension of Audiovisual (CHION, 2011). On the other hand, we can consider that a scenario of school violence can only exist in the absence of human rights. This work reflects on cinema in school, observing the concept of Educational Curatorship (VERGARA, 1996) as a key element in the fight against violence, and as a tool for guaranteeing an Education in human rights.

Keywords: Cinema; Education; Human rights. 
Resumen: El cine, la educación y los derechos humanos forman una tríada importante a partir de la cual debemos repensar nuestras prácticas docentes. El cine está presente en la escuela de varias maneras, pero el campo formado a partir de la unión del cine con la educación originó investigaciones que reflejan el cine en la escuela como la alteridad, cuestionando su uso como un mero soporte pedagógico. Los derechos humanos tienen una contribución fundamental para este proceso, ya que aportan a esta reflexión una dimensión ética y estética de Audiovisión (CHION, 2011). Por otro lado, podemos considerar que un escenario de violencia escolar solo puede existir en ausencia de derechos humanos. Este trabajo propone una reflexión sobre el cine en la escuela, observando el concepto de curación educativa (VERGARA, 1996) como elemento clave en la lucha contra la violencia y como garante de una educación en derechos humanos.

Palabras clave: Cine; Educación; Derechos humanos.

\section{Introdução}

A escola na contemporaneidade é objeto de inúmeras pautas. Estudos dentro do campo formado a partir da interseção cinema e educação vislumbram possiblidades interessantes de se arejar a escola a partir da arte, em geral, e do cinema, em especial. Nesse cenário, os direitos humanos entram como terceiro elemento, que pode transformar nosso entendimento do que pode o cinema na escola.

Este trabalho propõe uma reflexão sobre o cinema na escola, observando o conceito de Curadoria Educativa (VERGARA, 1996) como peça chave no combate à violência e como garantidor de uma Educação em direitos humanos. A violência aparece, aqui, como antônimo de direitos humanos, na medida em que estes surgem como garantidores da dignidade da pessoa humana, enquanto aquela se traduz como procedimento de coisificar o Outro. Pensar o cinema e a educação atravessados pelos direitos humanos está, nesse sentido, diretamente ligado à erradicação da violência no cotidiano escolar.

\section{Cinema, educação e direitos humanos: um encontro necessário}

Cinema, direitos humanos e educação: como buscar uma interseção entre esses campos? Partimos de uma reflexão sobre o cotidiano escolar para discutir as diversas formas de existência do cinema na escola e de que maneira os direitos humanos estão presentes hoje no espaço escolar. Para isso, pensamos na autonomia do professor e na importância da formação docente como definidores do modo como cinema e direitos humanos ocupam esse espaço.

Cinema e direitos humanos estão na escola como possibilidades de desconstrução das hierarquias marcadas pela disposição dos corpos e pelas relações de poder entre professores e alunos, diretores/coordenadores e professores, diretores/coordenadores e alunos, etc. É 
preciso pensar a escola como espaço democrático de maneira radical, tendo cinema e direitos humanos como centrais em nossas práticas pedagógicas.

Um passo além do caráter polissêmico dos direitos humanos, já clarificando o sentido de direitos humanos que defendemos e que se pauta pela igualdade na diferença, seu acréscimo à relação preexistente e em constante construção do cinema com a educação, é de fundamental importância, sobretudo quando percebemos que tanto a educação quanto o cinema (e a arte em geral) são atacados em momentos em que pensamentos reacionários ocupam o proscênio. Nesse sentido, cinema, educação e direitos humanos, juntos, funcionam como uma força importante para garantir que alunos, professores e demais atores sociais que desempenham alguma função dentro do universo escolar tenham não apenas os seus direitos fundamentais respeitados, mas contribuam para a construção de visões de mundo pautadas pelas noções de alteridade e de respeito à dignidade da pessoa humana.

Quando voltamos nossos olhares para a relação entre cinema e educação e as profícuas possibilidades de troca entre esses campos, muitos de nossos anseios reverberam desejos que são próprios dos direitos humanos. Pensar numa educação libertadora vinculada aos direitos humanos, na acepção de Paulo Freire (2019), é conceber um tipo de educação em detrimento de outros muitos tipos possíveis. Refletir sobre o que pode o cinema na escola, dentro dessa perspectiva, também significa assumir uma determinada forma de entender o cinema, como alteridade no espaço escolar, como elemento que promova a quebra das relações hierárquicas e o redimensionamento dos espaços tão marcados pela imobilidade das carteiras e do quadro na sala de aula.

É a partir dessa visão e para a consolidação desses anseios que promovemos a interseção entre cinema, educação e direitos humanos. Não se trata, pois, de uma Educação em direitos humanos voltada para o ensino e a memorização de determinada pauta. Não acreditamos que o cinema e a educação devam ser ponte para os direitos humanos dessa forma. Em vez disso, concebemos uma relação entre cinema e educação atravessada pelos direitos humanos, de maneira orgânica, matizando a união do cinema com a educação a partir de um determinado olhar sobre o mundo.

A Educação em direitos humanos surge como uma vertente que almeja a transformação da realidade por meio de estratégias que sustentem uma série de aprendizados voltados para a garantia do respeito à dignidade da pessoa humana, da valorização das diferenças e do combate às mais variadas formas de preconceito.

Educação em direitos humanos é um dos temas centrais da luta pelos direitos humanos hoje. Desde que a ONU definiu uma década pela educação em direitos humanos (19952004), os avanços nesse campo foram notáveis. Os Planos Nacionais de Educação em Direitos Humanos são decorrência direta desta década, mas há também controvérsias sobre como deve se dar essa educação em direitos humanos.

A maior preocupação da Educação em direitos humanos é, essencialmente, com a construção de uma cultura dos direitos humanos e de respeito à dignidade da pessoa 
humana. Essa construção se daria por meio da educação, pelo fomento aos valores de justiça, de liberdade, de igualdade, preservando e valorizando as diferenças. Resta claro que muitas das diretrizes da luta pelos direitos humanos, notadamente na educação, já habitam nossos pensamentos e pautam nossas ações, ainda que não utilizemos, necessariamente, o termo Educação em direitos humanos. Porém, o uso da expressão, que defendemos, evoca uma luta de décadas, para não dizer de séculos, de mulheres e homens engajados na educação, voltada para aquilo que é mais essencial aos direitos humanos: a dignidade da pessoa humana.

O propósito maior da Educação em direitos humanos gira em torno de uma educação libertadora e que emancipe os sujeitos, que os tornem cientes de seus direitos e dos direitos dos outros. Nesse sentido, não falamos de uma educação voltada para o adestramento, para a mera transmissão de conhecimento ou, ainda, que tenha o mercado de trabalho no horizonte. É uma educação que se destina à transformação social na medida em que se dedica a pensar os direitos humanos de maneira plena e orgânica na sociedade. Assim, formar para a vida com base no respeito à dignidade da pessoa humana é um fundamento essencial da Educação em direitos humanos.

No entanto, apesar dos esforços relacionados à elaboração dos planos nacionais de educação em direitos humanos, tanto em âmbito nacional quanto mundial, a escola não logrou uma forma efetiva de erradicação da violência que marca o cotidiano escolar. Em Direitos Humanos, Violência e Cotidiano Escolar, Vera Candau (2013) aponta para uma observação importante: a escola como produtora de violência (p.142). Na medida em que defendemos uma educação atravessada pelos direitos humanos, cabe perguntar de que maneira a violência habita a escola e como o cinema pode adentrar o espaço escolar crivado pelos direitos humanos.

Nesse sentido, vale refletir sobre a relação entre direitos humanos e violência para sustentarmos melhor de que forma a escola pode e deve existir plenamente como formadora de sujeitos de direitos.

\section{Direitos humanos e violência na escola}

Para pensarmos sobre o cinema a partir do contexto de violência na educação, é interessante, primeiro, analisarmos o conceito de violência para melhor entender sua ocorrência na escola. O fenômeno da violência acompanha a história da humanidade e faz parte do processo civilizatório. A violência pode ser efetivada tanto por agentes públicos e órgãos do Estado, quanto por indivíduos e grupos isolados. Segundo Marconi Pequeno (2016), o que há em comum entre todos os tipos de violência é o fato de atingirem o ser humano naquilo que ele tem de essencial: sua dignidade. Violência é, acima de tudo, um dispositivo destinado a coisificar o outro.

A violência é um tema complexo, que traz consigo uma carga polissêmica. Conceito, fenômeno, categoria acusatória, a violência é tratada por autores de diversas formas. Marino (2004), por exemplo, busca as origens sociais da violência, notadamente na América Latina, por 
meio do que ele chama de ciclos históricos da violência. Com uma abordagem diferente, Misse (2008) aborda a problemática da violência, especificamente no Rio de Janeiro, formulando a ideia de uma acumulação social da violência, entendendo a violência como uma espécie de síndrome da qual todos os atores sociais participam. Dessas duas perspectivas distintas, podemos perceber o quanto a questão da violência pode ser explorada e nos ajudar a pensar o mundo atual.

Charlot (2002) enfatiza a violência ligada ao uso da força. O desejo de aniquilar o outro, de dominar, de atormentar, estaria no cerne da problemática da violência. É a partir dessa abordagem, considerando a violência como algo concreto, que o autor pensa a violência na escola. Teríamos, então, três diagnósticos na relação violência e escola. A violência na escola seria aquela que não estaria ligada, de nenhuma maneira, à instituição. Seria uma violência do mundo que invade a escola por alguma razão. Por exemplo, se um grupo rival a algum aluno que estuda em determinada escola invade o espaço escolar para perpetrar um ato de violência contra esse estudante, teríamos um exemplo de violência na escola, da qual a instituição não participa.

Outra possibilidade seria a violência à escola, identificada por Charlot como uma violência direcionada contra a instituição, como quando um aluno agride um membro do corpo docente ou um funcionário, e ainda quando alunos provocam danos ao patrimônio, quebram carteiras, danificam as instalações ou, até mesmo, iniciam um incêndio. Sendo assim, é uma violência que busca atingir a instituição e aqueles que a representam.

Por fim, teríamos a violência da escola, que se dá quando a própria instituição é responsável pela violência, e que abrangeria desde a hierarquização das relações, a manutenção de hierarquias de poder, até a elaboração e a legitimação de sistemas de avaliação opressivos e que ignoram as subjetividades e o aprendizado como processo. Nesse sentido, essas três categorias da relação entre violência e escola colocadas por Charlot nos ajudam a pensar sobre como a violência realmente se dá na escola, ainda que essa classificação possa funcionar apenas como ponto de partida. De todo modo, o que nos interessa nesse estudo é pensar na violência da escola e sua relação com o cinema.

A escola convive com a violência, seja na invisibilização das desigualdades estruturais, seja na hierarquização entre seus atores sociais, ou ainda na aceitação de certas relações de poder que nos remetem a uma violência simbólica (BOURDIEU, 1989). Podemos considerar a equação colocada por Charlot, entendendo que a violência na e à escola convivem e precisam ser devidamente equacionadas (Charlot considera que a instituição é bastante impotente no que concerne à violência na escola, o que também podemos questionar), mas que é a violência da escola que merece especial atenção e que estabelece com o cinema uma importante relação.

Pensar o cinema nessa perspectiva nos ajuda a vislumbrar formas de combate à violência no âmbito escolar. Entre utilizar o audiovisual como instrumento ou encará-lo como um fundamento na educação (PRETTO, 2005), podemos estar diante de formas que perpetuam a violência ou, ao contrário, que ajudam a combatê-la. Em outras palavras, um filme pode 
ser exibido na escola como forma de perpetuar as desigualdades, o preconceito, o status quo, mas esse mesmo filme pode também ser exibido como provocador do efeito contrário, fazendo aflorar a igualdade na diferença, suscitando debates a partir de uma abordagem ética e estética da obra audiovisual, promovendo a afirmação das subjetividades.

Entendemos, então, que das duas maneiras básicas que o cinema pode entrar na escola, a saber, por meio da realização audiovisual ou da exibição, podemos considerar que ambas abrem a possibilidade de que o cinema atue de maneiras diferentes, até mesmo opostas. Ao reafirmamos o cinema como alteridade no espaço escolar, queremos, portanto, negar um uso que reduza a arte cinematográfica à condição de suporte para ensino de determinado conteúdo. Isso porque essa forma de instrumentalizar o cinema pode significar, também, uma forma de violência simbólica na medida em que silencia questões ou impede discussões vitais para a afirmação da diferença.

Como sabemos, se um professor decide realizar vídeo com os alunos, a relação que se estabelece entre eles poderá ser de total horizontalidade, promovendo o encontro do aluno com o cinema de maneira plena, mas também hierarquizante, na medida em que o professor poderá reduzir esse encontro a mais uma forma de domínio e de silenciamento. Da mesma forma, se esse mesmo professor opta por exibir um filme, ele poderá utilizar a obra cinematográfica como apoio para determinado conteúdo, mas poderá, também, mesmo dentro de determinada disciplina, promover um encontro do aluno com o cinema que possibilite uma situação de horizontalidade, de alteridade e de combate à violência.

\section{Cinema e direitos humanos na escola}

Nem sempre presente como se gostaria, o cinema na escola é constantemente instrumentalizado, reduzido a apoio às diversas disciplinas, sem que as promessas de um cinema como alteridade na escola se concretizem. Viabilizar a presença do cinema e do audiovisual na escola de maneira que a relação cinema e educação se dê satisfatoriamente pressupõe que o docente esteja preparado para tal, fazendo com que essa relação se dê de maneira plena. Quando pensamos na educação em direitos humanos como central na realidade atual, indagações sobre o papel do cinema na escola ajudam a vislumbrar os desafios que se colocam.

Uma relevante questão que surge quando se discute a formação docente em relação ao uso do cinema e do audiovisual na escola é o conceito de curadoria educativa. Segundo Luiz Vergara (2013), é por meio das escolhas feitas pelo professor que se pode promover, no âmbito escolar, uma experiência com a arte que seja enriquecedora. Para Vergara, a arte é um ponto de encontro que acontece em três tempos. Em primeiro lugar, é por meio da experiência perceptiva individual que o encontro com a arte se dá, e esse tempo 1 é marcado pelo estranhamento e/ou admiração em relação à obra de arte. No segundo momento, o encontro com a arte é marcado pelo ato crítico/perceptivo, que ocorre por meio da descrição/ 
reconhecimento. Esse tempo 2 é definido tanto por um movimento individual quanto coletivo. Finalmente, o tempo 3 assinala a emergência de um ser poético por meio da imaginação ativa. Assim, as associações e as interpretações sublinham a interação em grupo.

O que está em jogo na elaboração do conceito de curadoria educativa a partir de Vergara é a ideia de arte como ação cultural, como construção da consciência do olhar. Inicialmente considerando a arte contemporânea e o cotidiano, a curadoria educativa abre a possibilidade de pensarmos a relação cinema e direitos humanos numa perspectiva educacional.

A curadoria educativa é prática fundamental do trabalho docente na medida em que é necessário pensar e fazer escolhas que promovam experiências significativas com o cinema na escola. Miriam Martins (2006) também coloca a importância da escolha feita pelo docente que, segundo a autora, deve ser pautada por uma consciência do olhar, o que posiciona a curadoria educativa como central na formação docente. Quando pensamos a exibição audiovisual no espaço escolar, as questões iniciais que surgem são: quais filmes escolher? e de que maneira abordá-los? Essas indagações tornam indispensável pensar na formação docente. De que outra maneira o profissional da educação poderá extrair do encontro do cinema com a educação uma experiência que seja transformadora tanto para ele quanto para seus alunos? Os direitos humanos que, pelo marco regulatório do Plano Nacional de Educação em Direitos Humanos (2007), devem atravessar a educação surgem como elemento fundamental para estabelecer uma relação simbiótica entre cinema e educação.

Vera Candau e Susana Sacavino (2013) refletem sobre a importância da formação de professores, e atrelamos a formação docente a essas autoras por uma especificidade: no estudo de Candau e Sacavino, a formação de professores surge atravessada pelos direitos humanos. As autoras analisam o lugar da educação em direitos humanos no caso específico da América Latina e, também, buscam enumerar os desafios dessa formação docente. Esses desafios são colocados em sete pontos principais. Inicialmente, é preciso ressignificar a visão do senso comum, na qual encontramos uma verdadeira distorção do que se consolidou como a luta histórica dos direitos humanos. Essa distorção chega ao ponto de enunciar os direitos humanos pelo seu avesso, como ferramenta para a defesa de bandidos, colocando parte da opinião pública contra essa luta. Outrossim, as próprias autoras indicam a relevância de assumir uma concepção de direitos humanos, dada a polissemia do termo, deixando claro o que se quer atingir.

Além desses pontos, Candau e Sacavino mencionam a importância de articular ações de sensibilização e formação, bem como de construir ambientes educativos que respeitem e promovam os direitos humanos. Por fim, ressaltam a necessidade de incorporar a educação em direitos humanos no currículo escolar, e de introduzi-la na formação inicial e continuada, bem como estimular a produção de materiais de apoio.

Nesse sentido, a principal chave para a formação docente deveria ser a educação em direitos humanos, fornecendo elementos aos professores para que sua atuação no espaço escolar esteja sempre em sintonia com esse preceito. Tal formação tem repercussão direta 
no modo como o cinema entra na escola, uma vez que a curadoria educativa, tendo como premissa a ideia da arte como ação cultural, traz complexidade para a escolha e a abordagem dos filmes, seja em cineclubes, seja dentro de determinada disciplina. Assim, quando alinhamos cinema, educação e direitos humanos, as questões centrais que anunciamos anteriormente, como quais filmes escolher? e de que maneira abordá-los?, ganham profundidade.

Quando um professor escolhe determinado filme e decide exibi-lo aos seus alunos, ele tem uma intenção que pode se restringir ao conteúdo ministrado em suas aulas, ou pode assumir o cinema como arte, trazendo para a discussão uma abordagem ética e estética da obra audiovisual em questão. Com efeito, a curadoria educativa, conforme anunciada por Vergara, atrela a exibição audiovisual a essa segunda possibilidade, colocando a ação cultural como elemento central.

Consciente da relevância de se entender a arte como ação cultural, o professor promove o encontro entre cinema e educação, sustentando as diretrizes do Plano Nacional de Educação em Direitos Humanos e oferecendo aos alunos uma experiência que permita a construção de um novo olhar a partir da arte. Desde a relação individual que cada aluno estabelece com o filme exibido, até a etapa da interação em grupo na qual a obra audiovisual será debatida e ressignificada pela turma, o que se vislumbra, aqui, é uma maneira de unir cinema, educação e direitos humanos a partir da experiência ética e estética proporcionada pela curadoria educativa.

Levar o cinema para a escola e silenciar discussões que permitam uma abordagem ética e estética da obra audiovisual é abandonar as premissas da educação em direitos humanos na medida em que, assim, não se promove um ambiente educacional que permita o florescimento da diversidade, do ato crítico/perceptivo, do estranhamento e/ou da admiração diante da obra de arte. Fechar o alcance de um filme dentro dos limites de um conteúdo programático é, de certa forma, romper com uma educação em direitos humanos e seu encontro com o cinema.

Por conseguinte, a curadoria educativa, intrinsecamente relacionada à formação docente, que deve ser pensada dentro da perspectiva de uma educação em direitos humanos, surge como caminho a ser seguido para que professores, ao trabalharem com cinema no espaço escolar, estejam atentos às possibilidades de transformação de mundo a partir da experiência que proporcionam aos seus alunos. Cinema e educação, atravessados pelos direitos humanos, abrem importantes veredas que podemos trilhar. O cenário ainda raro de materiais de apoio e de ênfase na formação docente pautada pelos direitos humanos pode ser ampliado e decorado a partir de nossas pesquisas e reflexões, bem como de nossa atuação em sala de aula. A construção de novos mundos e consciências começa no momento de nossas escolhas e na certeza de nosso poder de transformação.

Entendemos, então, que das duas maneiras básicas que o cinema pode entrar na escola, a saber, por meio da realização audiovisual ou da exibição, podemos considerar que ambas abrem a possibilidade de que o cinema atue de maneiras diferentes, até mesmo opostas. Ao reafirmamos o cinema como alteridade no espaço escolar, queremos, portanto, negar um 
uso que reduza a arte cinematográfica à condição de suporte para ensino de determinado conteúdo. Isso porque essa forma de instrumentalizar o cinema pode significar, também, uma forma de violência simbólica na medida em que silencia questões ou impede discussões vitais para a afirmação da diferença.

Como sabemos, se um professor decide realizar vídeo com os alunos, a relação que se estabelece entre eles poderá ser de total horizontalidade, promovendo o encontro do aluno com o fazer cinematográfico de maneira plena, mas também hierarquizante, na medida em que o professor poderá reduzir esse encontro a mais uma forma de domínio e de silenciamento. Da mesma forma, se esse mesmo professor opta por exibir um filme, ele poderá utilizar a obra cinematográfica como apoio para determinado conteúdo, mas poderá também, mesmo dentro de determinada disciplina, promover um encontro do aluno com o cinema que possibilite uma situação de horizontalidade, de alteridade e de combate à violência.

Considerando a opção pela exibição cinematográfica, é instigante pensar como um mesmo filme pode provocar efeitos tão díspares e contrários. O encontro com o cinema precisa, então, ser objeto de reflexão contínua, e acreditamos ser a formação continuada a melhor maneira de municiar o professor para que o cinema possa estar na escola dentro de um ambiente de igualdade e de alteridade.

Existe um elemento fundamental no trabalho docente e que é marcado pela autonomia do professor. Paulo Freire (2015) elenca os saberes docentes necessários aos professores em Pedagogia da Autonomia, aos quais podemos somar a capacidade de pensar o cinema e o audiovisual de maneira crítica, ética e esteticamente, para que o trabalho com o cinema em sala de aula ocorra da maneira como alentamos.

Nesse sentido, é fundamental acreditar na formação docente. É ela que garantirá uma formação pautada pelos direitos humanos, fazendo com que o professor desenvolva em sala de aula o respeito à dignidade da pessoa humana, ao mesmo tempo em que promova a formação de sujeitos de direitos. É ela também que fornecerá ao professor as ferramentas para que o cinema e o audiovisual sejam motivadores constantes de reflexão para que a experiência com o cinema na escola seja transformadora e, sobretudo, não reproduza situações de violência.

Outro ponto fundamental é promover uma quebra das hierarquias que marcam o cotidiano escolar. O cinema, em especial, e a arte, em geral, podem funcionar como poderosos aliados dos professores nessa empreitada. O cinema em sala de aula, seja na exibição, seja na realização audiovisual, traz a possibilidade de reinventar os espaços e de redesenhar as relações. O fomento, por exemplo, às rodas de debates após a exibição de um filme e ao trabalho coletivo nas gravações de um vídeo é de grande importância para que a escola possa ser atravessada pelos direitos humanos.

Transformar a escola em espaço de democracia plena significa, antes de tudo, criar um ambiente no qual os sujeitos tenham voz, independentemente do lugar que esses sujeitos ocupem. Por isso é tão relevante criar um cenário possível para que as vozes ecoem e, principalmente, para que sejam ouvidas. É disso que se trata quando pensamos na escola como 
espaço radicalmente democrático. O silenciamento de vozes e pensamentos e, portanto, os atos de violência na escola podem vir, inclusive, por meio do cinema. Portanto, é indispensável refletir cada vez mais sobre cinema e educação, e ao agregarmos as preocupações próprias dos direitos humanos e do combate à violência nesse campo, antevemos novas possibilidades de análise.

\section{Considerações finais}

O cinema está na escola de diversas formas, mas não resta dúvida que ele apresenta uma potência que pode enriquecer nossas práticas pedagógicas. A partir do conceito de curadoria educativa, entendemos que, ao escolher um filme, o professor pode promover um encontro entre cinema e direitos humanos. Os pressupostos da Educação em direitos humanos que estão colocados precisam ser efetivados na escola, superando o hiato entre aquilo que é imaginado e o que realmente é colocado em prática. O cinema tem um papel importante nesse processo.

Nesse sentido, a curadoria educativa possibilita, ao mesmo tempo, a autonomia do professor na escolha dos filmes que ele quer trabalhar com seus alunos e, por meio da formação em direitos humanos, o professor pode também garantir que o cinema na escola esteja atravessado pelos direitos humanos, promovendo um efetivo combate à violência que marca o cotidiano escolar de diversas formas.

Direitos humanos e violência são, assim, excludentes. Um só pode existir na ausência do outro. Pensar o cinema como facilitador da entrada dos direitos humanos na escola cumpre a superação do hiato que separa as intenções previstas pela Educação em direitos humanos de nossas práticas docentes.

Os direitos humanos marcam a contemporaneidade. Lutar para que seus fundamentos estejam presentes na vida de todas e todos é garantir a efetivação da Educação em direitos humanos. Acreditar no potencial do cinema como fomentador dos direitos humanos na escola é caminhar rumo à construção de uma sociedade mais justa e igualitária, a partir da disseminação de uma cultura dos direitos humanos que começa a partir do redimensionamento do universo escolar.

\section{Referências}

BOURDIEU, Pierre. O poder simbólico. Rio de Janeiro: Bertrand Brasil S.A., 1989.

CANDAU, Vera. Direitos Humanos, violência e cotidiano escolar. In: CANDAU, Vera (Org.) Reinventar a Escola. Petrópolis, RJ: Vozes, 2013.

CANDAU, Vera.; SACAVINO, Susana. Educação em Direitos Humanos e Formação de Educadores. Educação, v.36, n.1, p.59-66, jan./abr. Porto Alegre, 2013. 
CHARLOT, Bernard. A violência na escola: como os sociólogos franceses abordam essa questão. Sociologias. Porto Alegre, ano 4, n. 8, jul./dez. 2002. Disponível em: https://www.researchgate. net/publication/26374055_A_violencia _na_escola_como_os_sociologos_franceses_abordam_ essa_questao. Acesso em: 07 mar. 2020.

CHION, Michel. Audiovisão: som e imagem no cinema. Lisboa: Texto e Grafia, 2011.

FREIRE, Paulo. Pedagogia da Autonomia: saberes necessários à prática educativa. Rio de Janeiro: Paz e Terra, 2015.

Direitos Humanos e educação libertadora: gestão democrática da educação pública na cidade de São Paulo. São Paulo: Paz e Terra, 2019.

MARINO, Juan. Ciclos Históricos da Violência na América Latina. São Paulo em Perspectiva, v.18, n.1, São Paulo, jan./mar., 2004. Disponível em: http://www.scielo.br/scielo.php?script=sci_ arttext\&pid=S0102-88392004000100005. Acesso em: 07 mar. 2020.

MARTINS, Miriam Celeste (Coord.). Curadoria educativa: inventando conversas. Reflexão e Ação - Revista do Departamento de Educação/UNISC, vol. 14, n.1, jan./jun. 2006.

MISSE, Michel. Sobre a acumulação social da violência no Rio de Janeiro. Civitas, Porto Alegre, v.8, n.3, set./dez., 2008.

PEQUENO, Marconi. Violência e Direitos Humanos. Revista de Filosofia Aurora, Curitiba, v.28, jan./abr. 2016.

PORTO, Maria. Crenças, valores e representações sociais da violência. Sociologias, Porto Alegre, ano 8, n. 16, jul./dez. 2006.

PRETTO, Nelson. Uma escola sem/com futuro: educação e multimídia. Campinas: Papirus, 2005.

VERGARA, Luís. Curadoria Educativa: Percepção Imaginativa/Consciência do Olhar. Encontro da ANPAP, São Paulo, 1996. 